\title{
Toward Pragmatically Naturalized Transcendental Philosophy of Scientific Inquiry And Pragmatic Scientific Realism
}

\author{
Sami Pihlström \\ Helsinki Collegium for Advanced Studies \\ University of Jyväskylä
}

\begin{abstract}
This paper seeks to show that the turn toward local scientific practices in the philosophy of science is not a turn away from transcendental investigations. On the contrary, a pragmatist approach can very well be (re)connected with Kantian transcendental examination of the necessary conditions for the possibility of scientific representation and cognition, insofar as the a priori conditions that transcendental philosophy of science examines are understood as historically relative and thus potentially changing. The issue of scientific realism will be considered from this perspective, with special emphasis on Thomas Kuhn's conception of paradigms as frameworks making truth-valued scientific statements possible and on Charles $S$. Peirce's realism about "real generals".
\end{abstract}

Keywords: realism, naturalism, pragmatism, scientific realism, transcendental philosophy, Kuhn

\section{Introduction}

Philosophy of science has over the past couple of decades-following successful interdisciplinary inquiries in science and technology studies, in particular-taken the concrete local practices of historically contextualized scientific inquiry much more seriously than more traditional philosophies of science, such as logical empiricism and its follow-ups, including standard versions of scientific realism and neo-Kantian social constructivism, ever did. Attempts to understand the nature of science have thus shifted from "global" questions of justification, for example concerns with the logical

Corresponding author's address: Sami Pihlström, Helsinki Collegium for Advanced Studies, P.O. Box 4, FI-ooo14 University of Helsinki, Finland. Email: sami.pihlstrom@helsinki.fi. 
structure of scientific theories, scientific inference, and scientific explanation-concerns arguably culminating in what may be regarded as "transcendental" issues concerning the very possibility of cognitive experience or scientific knowledge and representation-to more "local" issues of, say, modeling and other epistemic activities whose central cognitive goals and strategies are strongly practice-embedded and even unintelligible without a practical context.

This shift, though understandably resisted by traditional philosophers of science fearing the excesses of relativism, is in many ways a welcome one. However, it is very important to realize that the shift from the global to the local is not inevitably a move to a completely non-transcendental approach to science. By developing this point I will, in the following, also argue, at a more general level, for the compatibility and even the mutually enriching potential of the pragmatic and the transcendental perspectives on science.

\section{The pragmatic and the transcendental}

I want to begin by arguing that taking local scientific practices seriously does not automatically mean that one is a resolutely non-Kantian philosopher in one's account of scientific inquiry. This is because the Kantian or quasiKantian "transcendental" element-whatever it is that must be presupposed for inquiry, representation, or cognition to be possible-may lie in the local practices themselves. ${ }^{1}$ This is an insight that may be developed through a Kantian reading of Thomas Kuhn's work, in particular. Kuhn, after all, was a major figure-perhaps the most important figure-behind the "practice turn" of contemporary philosophy of science and science and technology studies. (Cf. Kuhn 1970, 2000; see also Pihlström and Siitonen 2005)

According to Kuhn's well-known statement, the notion of truth, insofar as it has anything to do with the developments of science and scientific theories, cannot be "extra-theoretical" correspondence but must instead be understood "intra-theoretically" (Kuhn 2000, 115, 160-162, 251). This does not mean any naïve anti-realism or constructivism, however. There is a sense in which the world is "experientially given" and "solid", instead of being something that we (or the scientists) simply "make up" (Kuhn 2000, 101). Even in Kuhn's late work, there is, nevertheless, a version of the famous idea of

\footnotetext{
Generally, Kantian transcendental philosophy-following Kant's (1781/1787) discussion of the necessary conditions for the possibility of cognitive experience-engages in inquiries into necessary conditions for the possibility of certain given human actualities, such as (in addition to experience, Kant's main concern) linguistic meaning (Wittgenstein) or scientific representation. It is always controversial to read later thinkers as "Kantian" or "transcendental"; my suggestions in this regard must therefore be regarded as provisional and suggestive rather than aiming at historical accuracy.
} 
different paradigms constituting "different worlds" (cf. Kuhn 1970, 111, 206): he does speak about the "world-constitutive" role of human intentionality and mental representations (Kuhn 2000, 103). The world is in some sense constituted or structured, if not literally constructed, by the human mindor, more specifically, by scientific theorization and other epistemic activities, both srictly scientific and more loosely everyday ones.

In this way, Kuhn does seem to argue, early and late, that local scientific practices are in the business of world-constitution. Indeed, the plausibility of the Kuhnian view of the world-constitutivity of paradigms and intratheoretical truth seems to depend on the availability of a Kantian interpretation and/or reconstruction of Kuhn's occasionally more than just mildly obscure statements. Kuhn himself admitted in his late work that he had developed "a sort of post-Darwinian Kantianism", with "the lexicon" supplying "preconditions of possible experience" in a way analogous to the Kantian categories, yet differing from the latter by being relative to both time and community (Kuhn 2000, 104). Kuhn should, then, be read as a Kantian with "movable categories" (Kuhn 2000, 264) and without any permanently existing things in themselves (see Kuhn 2000, 207); his "structured lexicon" and Kant's "a priori" may both, in a relativized sense, be taken to be "constitutive of possible experience of the world" without assuming that they could dictate what that experience must be in any concrete case (Kuhn 2000, 245).

Yet, again, something analogous to the Kantian thing in itself must be at work even in Kuhn's system, because "something permanent, fixed, and stable" must be what underlies the changes of lexical categories (Kuhn 2000, 104); anomalies requiring readjustments in scientific theories and paradigms could hardly occur at all, if everything there is were simply dependent on or constructed by us. There is, then, a curious combination of realism and idealism (constructivism) to be found in Kuhn-at least as profoundly as there is such a combination in Kant himself, who famously sought to integrate transcendental idealism with empirical realism and to avoid both dogmatic transcendental realism and skeptical empirical idealism. While the Kuhnian philosopher of science clearly need not employ this Kantian terminology, something like a Kantian vocabulary does seem to be required to make sense of the basic idea of the world being both ("transcendentally") dependent on scientific practices and ("empirically") independent of them; without a Kantian background this hardly makes sense at all. ${ }^{2}$

2 For more comprehensive discussions of Kuhn's relation to realism, constructivism, and Kantianism, see, e.g., (Hoyningen-Huene 1993), (Andersen 2001), (Friedman 2001, 2002, 2003), and (Sharrock and Read 2002). Nothing in my elaborations in this paper depends on getting Kuhn historically right; in particular, I do not want to take any final stand on the question of whether Kuhn offers novel ideas in the realism debate or leads us out of 
Hence, we can now reach a conditional conclusion: if we want to make sense of Kuhn's view, that the way the world is, is paradigm-relative (captured in the slogan that "the world changes" in a scientific revolution), or the related view that local practices of inquiry play a constitutive role in the emergence of scientific truths, facts, and objects, we should understand the relevant notions of paradigm-relativity and constitutivity in a (quasi)Kantian transcendental sense, analogously to the way in which the objects of possible experience are, according to Kant himself, constituted by the categories (that is, the pure concepts of the understanding) and the forms of intuition.

\section{Kuhn and pragmatism}

A key observation at this point is that the kind of Kantian reading of Kuhn sketched in the previous section is not inevitably non-pragmatist. We may, in a broad sense, understand both Kuhn's account of scientific paradigms and the more general practice-oriented conception of science in contemporary philosophy of science and science and technology studies as "pragmatist". However, pragmatism can be a transcendental approach, too, as soon as we realize that the contextually necessary transcendental conditions for the possibility of cognitive experience (or, better, scientific representation of objective reality) are themselves practice-laden and historically revisable. While the classical pragmatists-Charles S. Peirce, William James, John Dewey, and others-were often highly critical of Kant (just think of James's pronouncement that the path of philosophical progress should be seen as moving from the British empiricists "round Kant", instead of "through Kant", to pragmatism), this is in my view partly based on their possibly somewhat limited self-understanding, as well as their limited understanding of what has proven to be most important and sustainable in Kantian philosophy (see, e.g., Pihlström 2003, 2008, 2009).

No obvious historical lines of influence can be traced from the classical pragmatists to Kuhn. However, Kuhn can, arguably, be interpreted-and has been interpreted by Michael Friedman and others-as joining, either explicitly or implicitly, if not those older pragmatists' views, at least the quasipragmatist ideas later made famous by thinkers like Ludwig Wittgenstein and C.I. Lewis (as well as, possibly, Michel Foucault) concerning the historically relative "a priori". Kuhnian paradigms (or lexicons) play this reconceptualized a priori role as enabling (making possible) scientific representation, and thereby also enabling scientific objects and truths to emerge from scientific practices and theorizing. Kuhn's position can, by synthesizing Kantian 
and pragmatist insights, be generalized into a more comprehensive version of historicized and naturalized ("pragmatized") transcendental idealism and transcendental philosophy of science. (Cf. Pihlström 2003, 2004; Pihlström and Siitonen 2005) Pragmatists more generally should be read as Kantian philosophers in the sense that they also challenged and continue to challenge transcendental realism, the supposition that the world possesses its "own" categorial ontological structure that our schemes and theories, or our science, can be expected to "cut at its joints", i.e., to simply reveal (or to fall short of revealing) "as it is in itself" and that could at least in principle be accurately represented in an absolute theory (and cannot be so represented if we lack an absolute theory). ${ }^{3}$

It is extremely important to give up the apodicticity, unrevisability, and universality of Kantian transcendental principles, in order to re-entangle Kantianism and pragmatism in a way that preserves the constitutive function of those principles. As Friedman (2001,30) explains, these principles need not be unrevisable in order to remain "constitutive of the concept of the object of knowledge." One of the most important versions of this "relative a priori" is Lewis's (1923) theory of the "pragmatic a priori" (cf. Järvilehto 2011). Its relations to Kuhn's ideas would deserve closer historical and systematic scrutiny.

However, this is not the right place to continue scholarly debates on what pragmatism actually means, either historically or systematically (see, e.g., Pihlström 2011c); nor am I in this paper willing to return to the question of how exactly to write the history of pragmatist philosophy of scienceassuming that there even is such a history to be coherently written (cf. Pihlström 2008). Clearly, it is not necessary to adopt the concept of pragmatism at all in one's interpretations of either Kuhn or the practice-oriented philosophy of science more generally. Perhaps the label "pragmatism" in the end adds very little to the key idea of focusing on scientific practices. Nevertheless, it does seem to me that the ways in which the realism debate, in particular, have been continued in the pragmatist tradition-and carried on and transformed into a pragmatic shape from the Kantian transcendental tradition-offer illuminating comparisons to Kuhn and many post-Kuhnian philosophers of science who have taken the "practice turn".

Joseph Rouse (2003) is one of the interpreters of Kuhn insightfully drawing due attention to Kuhn's role in emphasizing science as a practice. Rouse takes this to mean that Kuhn rejected the traditional epistemological questions of justifying scientific beliefs. However, while it is certainly correct

3 The modern version of this view, already rejected by Kant, would be "metaphysical realism", firmly rejected by Hilary Putnam and his many followers in the contemporary realism debate. See, e.g., (Putnam 1981, 1990). 
to note that the traditional issue of epistemic justification is not central in Kuhn, this seems to presuppose an unpragmatic dichotomy between practices and beliefs, whereas the more obviously pragmatist response to the traditional questions of justification would be the insistence that beliefs are practices-or, as the classical pragmatists themselves often put it, "habits of action". The view that beliefs are habits of action is one of the fundamental ideas of pragmatism all the way from the initiation of the pragmatist tradition by Charles S. Peirce and William James: beliefs are something on the basis of which we are prepared to act. Thus, it is somewhat problematic that, after perceptively pointing out that Kuhn leads us to a shift toward a description of science as an activity (rather than as a product of an activity), Rouse continues to claim that paradigms ought to be understood as "exemplary ways of conceptualizing and intervening in particular situations", instead of being understood "as beliefs (even tacit beliefs) agreed upon by community members" (Rouse 2003, 107).

From a pragmatist point of view, we may and should say that it is precisely in virtue of their being "ways of conceptualizing and intervening" that paradigms are also beliefs, or networks of beliefs-or perhaps "webs of beliefs", to employ a Quinean phrase (cf. section 4 below). It is in our goaldirected activities and practices themselves that our ontological ways of taking the world to be in some particular manner are to be located. There are, and can be, no beliefs at all apart from such activities and practices. Beliefs are inevitably based on practical contexts of inquiry, as the very purpose of inquiry is the fixation of belief, or the settlement of a problematic situation, and what this pragmatically involves is the acquisition of a new habit, or a revision of an already established one. Rouse's dichotomies between "practitioners" and "believers" and between "beliefs and forms of life" (Rouse 2003, $109,112)$ are, then, simply too unpragmatistic to be helpful in the context of my "transcendentally pragmatist" re-reading of Kuhn (and Kuhnian philosophy of science generally). Scientists, pragmatically speaking, are both practitioners and (hence) "believers".

${ }^{4}$ Accordingly, while Rouse's reflections are generally very helpful in integrating (pragmatic) naturalism with irreducible normativity within scientific practices (see also Rouse 2002), he offers no adequate historical treatment of pragmatism (which, of course, is not to say that he would have to do so...). As a matter of fact, I suggested already some time ago (see Pihlström 1998, chapter 9) that Rouse's earlier (Rouse 1996) proposals for a "postmodernist" philosophy of scientific practice could at least in part be cashed out in terms of (Deweyan) pragmatism. See also (Pihlström 2008). 


\section{Pragmatism as naturalized transcendental philosophy: holism and interdisciplinarity}

Pragmatism can, then, be rearticulated as a form of naturalized transcendental philosophy, both generally and in the context of contemporary philosophy of science, in particular. (And Kuhn himself, arguably, was a kind of pragmatist in this sense.) A further interesting analogy, drawn more directly from within the pragmatist tradition, could also be suggested here: Morton White's $(1956,1986,2002)$ holistic pragmatism can be seen as a version of the kind of pragmatically naturalized and historicized transcendental philosophy of science that the "local practices" approach in the philosophy of science today could utilize (although White himself might not be entirely satisfied with this characterization). Historical and systematic comparisons between Kuhn and White should be encouraged; very little work has so far been done in this regard. Kuhnian paradigms could be seen as practiceembedded sets of factual and normative assumptions governing inquiry in a given discipline or field, along the lines of White's holistic pragmatism. Irreducible normativity, which is crucial for scientific practices to be rationally constrained, is to be found within paradigms themselves, not external to them.

White agreed with W.V. Quine already in the late 1940s and early 1950 s that there is no sharp, essentialist dichotomy to be drawn between analytic and synthetic statements (see White 1956). However, he extended this holism to cover the relation between factual and normative statements, which-in contrast to Quine-he also saw as entangled (White 1986); ultimately, this leads to a comprehensive holistic philosophy of culture in which science as well as ethics, law, and history, among other fields of inquiry, are seen as constituting a single overarching "web" (White 2002; cf. Pihlström 2011a). This is a web of beliefs as much as a web of practices and activities of inquiry, going very well together with the classical pragmatists' broad notion of inquiry, which covers not only science as conventionally understood but also ethics, politics, and even religion.

Moreover, such "webs" are historically developing entities, also in a way comparable to traditions, which clearly brings them close to Kuhnian paradigms. It is only within such a context-a paradigm, a web, a network - that something can count as a belief that could have a truth-value, as a way the world can be taken to be. So, we are here dealing with a transcendental issue again. The ways in which we are intentionally, experientially, and representationally connected with the world we inquire into through our webs of beliefs and practices are ultimately transcendental. They enable us to engage in our cognitive endeavors, both scientific and everyday ones. The world is never just "given" to us independently of such practice-laden, normatively 
constrained engagements. The webs of beliefs we may act upon are frameworks in terms of which the world can be scientifically represented.

The concept of interdisciplinary inquiry is particularly crucial here. One might even argue that White's holistic pragmatism itself is not just a philosophical but an inherently interdisciplinary approach to inquiry. The sciences and the humanities, in particular, are parts of the same holistic web of rational inquiry into the world we live in, just like science and ethics are. A holistic pragmatist conception of interdisciplinarity should be able to integrate naturalism (or the legitimate emphasis on the natural sciences and their significant achievements) with something like humanistic "constructivism" (human self-interpretation and self-transformation) into a single, yet pragmatically pluralistic and open-ended, image of our rational inquiries into the nature of things, ourselves included. If, when engaging in such inquiries, one is literally surrounded by colleagues representing different disciplines, one may also be better equipped to understand one's own inquiry as interdisciplinary; one may even cease to view oneself (or others) as a representative of a single discipline and rearticulate one's own position in the field of inquiry as irreducibly interdisciplinary.

I am not here pretending to know exactly what interdisciplinarity is, or how it should be defined. One key aspect of the pragmatist and fallibilist rejection of "first philosophy" (following Quine and White, as well as Kuhn and other practice-oriented philosophers of science) is, in any event, the acknowledgment of the need for deepening interdisciplinarity-not only multidisciplinarity-in our inquiries into the world and ourselves, including our inquiries into what scientific inquiries themselves are and should be like. One reason why holistic pragmatism is an inherently interdisciplinary approach in these inquiries (as I suggested above) is that pragmatists ought to oppose all dichotomies and boundaries that may "block the road of inquiry" (quoting Peirce's famous words). Traditional disciplinary boundaries may be such blocks. They may, by blocking the road of inquiry, even block the emergence of certain kinds of scientific facts or objects that (only) an interdisciplinary paradigm makes possible.

Of course, in practice there may be cases in which it is difficult to determine what exactly interdisciplinarity should mean and how it ought to be promoted in practices of inquiry, or academic institutions. For example, in interdisciplinary research institutions, in practice at least three alternative "readings" of the requirement to promote interdisciplinarity, significantly varying in strength, might be implemented. (i) Each individual scholar and/or research project might be required to be internally interdisciplinary (though possibly there can be degrees in the strength of their interdisciplinarity). Thus, no scholar or research project should, according 
to this formulation, represent just a single academic discipline but would have to represent at least two (or, perhaps preferably, more). (ii) According to a somewhat weaker interpretation, an individual scholar and/or project could represent just one discipline, but they would have to be open to interdisciplinary relations to other disciplines. There would thus have to be interdisciplinary potential in a research proposal, even though it would not have to be internally interdisciplinary. (iii) Only the interdisciplinary research institution as a whole would, according to the weakest interpretation, be required to be truly interdisciplinary. This would allow individual scholars and/or their projects to be even relatively strictly "disciplinary", but their combination would be expected to be such that (perhaps unexpected) interdisciplinary cooperation might grow out of it. (I am not saying, of course, that these three options exhaust all the alternative formulations of interdisciplinarity.)

Now, how should the correct strength of the interdisciplinarity expectation (either in the case of an individual or in the case of a community of scholars) be determined? Does pragmatism, e.g., White's holistic pragmatism or Kuhnian practice-oriented philosophy of science, help us in this regard? There is no immediate answer to the question of how strong interdisciplinarity pragmatism should promote. On the contrary, this is itself a contextually pragmatic matter, to be determined through a holistic critical consideration of the practices in question, in relation to other practices forming our cultural "web", as well as the purposes of the inquiry we are engaging in. The pragmatic value of interdisciplinarity should, moreover, always be relativized to the aims and goals of the particular inquiry (or practice) thus contextually and holistically considered. An obvious example of philosophical interdisciplinarity is the debate over naturalism-a debate to which pragmatists since Dewey have made major contributions and to which Rouse (2002) offers one of the most balanced reactions in the contemporary discussion - which cannot be settled independently of a vast variety of other philosophical and metaphilosophical issues, ethical and political ones included.

At this point of our discussion, it goes without saying that wide-ranging philosophical issues such as naturalism and interdisciplinarity are, in my view, also "transcendental" issues in the reinterpreted pragmatic sense explicated above. They are in the end issues concerning our being able to meaningfully represent reality. Furthermore, it has sometimes been suggested that, far from there being a sharp separation between the humanities and the natural sciences, all sciences are actually "human sciences". Natural sciences like physics are themselves oriented to the world on the basis of human interests and needs. These are not "nature's own" perspectives-recall again 
not just Kuhn but Kant and the classical pragmatists, too-but, inescapably, human ones. They are, as much as the traditional humanities, expressions of human self-interpretation. This is also something that pragmatists attracted by White's holistic pragmatism could and should spell out in more philosophical detail, while including philosophy-as well as metaphilosophyitself in the practice-embedded web of beliefs to be holistically tested. Science is part of human culture, and when critically examining the normative structures of academic practices of inquiry, we already operate within holistic pragmatism, ultimately evaluating the "unified whole" of human culture more generally, i.e., our ways of being in the world and categorizing and inquiring into the world in and through the cultural practices we have developed and are continuously developing. ${ }^{5}$

\section{Scientific realism?}

At least one major philosophical question remains to be considered: scientific realism. As I have suggested above, pragmatism can, generally, be understood as synthesizing something like transcendental idealism (in its naturalized and historicized, thus contextually relativized, reincarnation) with empirical realism. This is a further indication of its deep commitment to a Kantian approach in the project of conceptualizing our cognitive and representational relations to reality. It should, thus, be easy to appreciate both the Kantian and the pragmatist aspects of not only Kuhn's conception of science but also, say, Putnam's internal realism (cf. Putnam 1981, 1990).

In the realism debate, there is, of course, a wide variety of different views to consider-almost all of which must simply be ignored here. For instance, how exactly the pragmatist and Kantian elements of what I have called "pragmatic realism" (cf., e.g., Pihlström 2008) might be incorporated in the slightly different position known as "practical realism" (Vihalemm 2011) remains to be discussed elsewhere. I suppose that Rein Vihalemm's practical realism differs from my approach in being more distant from the Kantian transcendental concerns-and therefore in a sense "more realistic" (and at least not idealistic even in a reinterpreted sense). Yet, it seems to me that a very basic transcendental issue concerning the practice-laden representability and experienceability of reality must be taken up from the perspective of practical realism, too: according to Vihalemm's practical realist, scientific objects can, after all, only be identified within scientific practices. Thus, it would seemat least this rearticulation should be available to the "Kantian pragmatist" that practices provide transcendental (contextual) conditions for the possi-

5 This interpretation and elaboration of White's holistic pragmatism is more comprehensively developed in (Pihlström 2011a). 
bility of there being scientifically representable objects at all-for us. This also sounds very much like Dewey's (e.g., 1929) view that scientific objects are not "ready-made" prior to inquiry but rather arise out of, or are constructed and/or identified in the course of, inquiry.

In addition, it must be observed that the problem framework of scientific realism raises issues not just concerning the traditional opposition between realism and idealism (today reconceived as the debate between realism and constructivism) but also concerning the ones between realism and relativism (compare the discussion of the "relativized a priori" above in section 3 ) and even realism and nominalism. I have commented on these issues, also in relation to the philosophy of science and its history-with the particular goal of understanding better the development of pragmatist philosophy of science in the twentieth century-on a number of earlier occasions (e.g., Pihlström 2008, 2011b), so I will be very brief and selective here.

In the case of the realism vs. nominalism dispute, which might seem to be relatively far removed from the central issues in contemporary philosophy of science (it sounds more than slightly medieval, does not it?), the crucial question for a pragmatic realist and transcendental pragmatist is this: is there a viable analogy of (pragmatic) transcendental idealism and empirical realism when it comes to the special issue of realism about universals (or what Peirce called "real generals", e.g., laws and habits) ${ }^{6}$ and/or modalities, both of which are crucially important in an adequate conception of scientific inquiry as an inquiry into something "real"? In previous works (Pihlström 2003, 2009), I have offered a pragmatic-constructivist (albeit naturalized transcendental) account of Peircean "real generals", acknowledging their reality but interpreting this reality only in a practice- and discourseinternal sense-that is, as something ultimately humanly "constructed" (cf. also, e.g., Margolis 2010). The key idea here is that real generals, such as natural laws and dispositions, must be postulated in order to make sense of the scientific pursuit of truth, including truth about general laws and regularities, but this is nevertheless our human way of making sense of-or inquiring into what we find necessary conditions for the possibility of-our practices of inquiry.

Now, while something like this is certainly a philosophical view of real generals fitting "local" practice-oriented philosophy of science and science and technology studies-a realism about real generals that is analogous to "mere" empirical realism and therefore well compatible with transcendental idealism or constructivism (pragmatism) - we must still pause to reflect

${ }^{6}$ For more details, see Peirce's early and late writings on "real generals"-all the way from the late 1860 s to $1905-1907-$ collected in (Peirce 1992-1998). For references to relevant scholarship, see also (Pihlström 2009, chapter 6). 
on whether the position we have arrived at is plausible or even coherent. Stronger Peircean realists may argue that pragmatism itself, given its method of focusing on the "conceivable practical effects" of our ideas, concepts, conceptions, and theories, ${ }^{7}$ presupposes in a more full-blown sense the basic commitments of what Peirce called "extreme scholastic realism", i.e., realism about generality, including modalities. This is, arguably, because a realistic interpretation of possibility, in particular, is needed in order to account for "conceivable practical effects". The conceivable effects our ideas may have include effects never concretely realized in actuality.

This sounds heavily metaphysical but is in fact a vital issue for pragmatist philosophy of science, too, not just for pragmatist metaphysics. Are, for instance, physical or chemical laws and other structures Peircean-like "real generals"? If so, is it plausible to claim that they are still somehow transcendentally dependent on our inquiry, in a (pragmatically reinterpreted) Kantian-like sense? Are natural laws, in particular, nomically necessary in a realistic sense; are they also "real generals"? And even if they are, are not they also metaphysically (as well as, of course, logically) contingent, as the law-like structure of the world could presumably have been very different from what it de facto is? What is, furthermore, the relation between scientific representations (contextualized in our inquiries) and the laws that are from the point of view of our scientific theories claimed to "really" obtain in the world?

These issues remain open here; in any event, my general proposal is that real generals can and should be regarded not as features of the world an sich-any more than our theories or representations can ever be about things in themselves, either according to Kant or according to Kuhn-but as features of the-world-as-seen-through-the-practices-of-inquiry (whatever that ultimately concretely means). For example, physical or chemical structures could be seen as both real (that is, as real generals independent of our representations in an empirical sense) and as constructed (that is, as practice- or paradigm-relative, or at least identifiable only within practices or paradigms, in the pragmatically naturalized transcendental sense). More work clearly needs to be done here.

One way of pragmatically "cashing out" the idea that what there is depends on our epistemic and representational activities and practices of inquiry—or, in Kuhnian terms, on our paradigms - and the related idea of in-

7 This is not the proper place to inquire into the meaning of the pragmatic method or pragmatic maxim, first formulated by Peirce in his 1878 essay, "How to Make Our Ideas Clear" (reprinted in Peirce 1992-1998, vol. 1), and later employed by James, among others (see especially James 1907, chapter 2). For an updated discussion, see the relevant contributions to (Pihlström 2011c). 
tegrating transcendental idealism (constructivism) with empirical realism, through pragmatism, is what I have elsewhere called the "contextualization of scheme-(in)dependence" (see Pihlström 2011b). The basic idea here is that nothing is scheme- or practice- (or paradigm-) dependent or -independent as such, "in itself", but only in one or another context of practice-driven inquiry. Hence, the contextuality and relativity of a priori principles (cf. section 3 above) is in a way taken to the meta-level of philosophical interpretations of transcendental philosophy and the notions of scheme- or practicedependence and scheme-independence themselves.

Even so, the question concerning realism about generality, particularly about real possibilities and other modalities, must be left unresolved here. Philosophers of science often find it necessary to invoke irreducibly modal notions in order to make sense of the idea that the world could be, or could have been, structured in terms of quite different practice-embedded theories and paradigms than the ones we actually have at our disposal. ${ }^{8}$ Somehow modalities must already be incorporated in practices themselves, so it is not enough to simply say that a (moderately) realistic interpretation of modalities is just based on our practices. After all, practices are contexts within which things can be done in certain ways-or occasionally left undoneand this clearly means that they are, in Peircean terms, "generals". So are Kuhn's paradigms. So are any contexts that can play the transcendental role of pragmatically enabling scientific representation of objects, in the sense outlined in the early sections of this paper.

\section{Conclusion}

The relevance of all this relatively abstract and general discussion to both the interdisciplinary field of science and technology studies (or other practiceoriented reflections on the nature of science) and to special fields within the philosophy of science, e.g., the philosophy of chemistry, of biology, or of the social sciences, must remain implicit. However, the general issue of realism and the questions concerning the pragmatic naturalizability of transcendental approaches to that issue could presumably easily be illustrated in terms of more specific problems drawn from current discussions in these fields.

${ }^{8}$ For example, Rom Harrés suggestion that the world, "prior to" conceptualization and measurement (or the application of an apparatus of investigation), is somehow a world of "affordances", potentialities, or powers, comes close to a view admitting Peircean real generals. However, Harré emphasizes that these potentialities are not exactly "in" the world itself prior to its being subjected to an investigation involving our apparatuses; they are properties of "the world plus the apparatus". This makes his view clearly pragmatic (yet, in my view, also transcendental). I am indebted to many discussions at the Tartu workshop for being able to appreciate these connections. 
Pragmatism, I have tried to argue in this paper (and in some more detail, albeit in somewhat different contexts, in several previous publications), is a highly promising philosophical (and metaphilosophical) perspective in these inquiries, but it needs both updating in terms of interdisciplinary, "localized" investigations of scientific practices (e.g., from the perspective of science and technology studies as a "successor" of traditional philosophy of science) and Kantian backing, or what might be called "retranscendentalization". We must not forget that, even when dealing with "local" issues of the identifiability of objects within practices and the roles that our practices and/or paradigms (may) play in the constitution of reality as knowable and representable by us we are dealing with transcendental topics. Philosophy of science does not, and must not, give up those fundamental traditional concerns simply by turning pragmatic and non-foundationalist; through that turn it merely reinterprets them in novel ways.

\section{Acknowledgements}

This paper was presented at the workshop, Practical Realism (University of Tartu, Estonia, June, 2011). I am grateful to Endla Lõhkivi and the other organizers of the event, as well as to Rom Harré, Joseph Rouse, and Rein Vihalemm for very useful comments on my presentation in Tartu.

\section{Bibliography}

Andersen, H. (2001). On Kuhn, Wadsworth, Belmont.

Dewey, J. (1929). The Quest for Certainty: A Study on the Relation between Knowledge and Action, G.P. Putnam's Sons.

Friedman, M. (2001). Dynamics of Reason, CSLI Publications, Stanford.

Friedman, M. (2002). Kant, Kuhn, and the rationality of science, Philosophy of Science 69: 171-190.

Friedman, M. (2003). Kuhn and logical empiricism, in T. Nickles (ed.), Thomas Kuhn, Cambridge University Press, Cambridge, pp. 19-44.

Hoyningen-Huene, P. (1993). Reconstructing Scientific Revolutions: Thomas S. Kuhn's Philosophy of Science, The University of Chicago Press, Chicago.

James, W. (1907). Pragmatism: A New Name for Some Old Ways of Thinking, Harvard University Press.

Järvilehto, L. (2011). Pragmatic A Priori Knowledge: A Pragmatic Approach to the Nature and Object of What Can Be Known Independently of Experience, 
PhD thesis, University of Jyväskylä, Department of Social Sciences and Philosophy.

Kant, I. (1781/1787). Kritik der reinen Vernunft.

Kuhn, T. S. (1970). The Structure of Scientific Revolutions, University of Chicago Press, Chicago.

Kuhn, T. S. (200o). The Road since Structure, University of Chicago Press, Chicago.

Lewis, C. I. (1923). A pragmatic conception of the A Priori, The Journal of Philosophy 20: 169-177.

Margolis, J. (2010). Pragmatism's Advantage: American and European Philosophy at the End of the Twentieth Century, Stanford University Press, Stanford.

Peirce, C. (1992-1998). The Essential Peirce, Indiana University Press, Bloomington and Indianapolis.

Pihlström, S. (1998). Pragmatism and Philosophical Anthropology: Understanding Our Human Life in a Human World, Peter Lang, New York.

Pihlström, S. (2003). Naturalizing the Transcendental: A Pragmatic View, Prometheus/Humanity Books, Amherst.

Pihlström, S. (2004). Recent reinterpretations of the transcendental, Inquiry 47: 289-314.

Pihlström, S. (2008). How (not) to write the history of pragmatist philosophy of science?, Perspectives on Science 16: 26-69.

Pihlström, S. (2009). Pragmatist Metaphysics: An Essay on the Ethical Grounds of Ontology, Continuum, London.

Pihlström, S. (2011a). Morton White's philosophy of culture: Holistic pragmatism and interdisciplinary inquiry, Human Affairs 21: 140-156.

Pihlström, S. (2011b). The problem of realism, from a pragmatic point of view: On the contextuality of scheme-(in)dependence in pragmatism, in R. Frega (ed.), Pragmatist Epistemologies, Lexington Books / Rowman \& Littlefield Publishing Group, Lanham, pp. 103-126.

Pihlström, S. (ed.) (2011c). The Continuum Companion to Pragmatism, Continuum, London.

Pihlström, S. and Siitonen, A. (2005). The transcendental method in the philosophy of science, Journal for General Philosophy of Science 36: 81106.

Putnam, H. (1981). Reason, Truth and History, Cambridge University Press, Cambridge. 
Putnam, H. (1990). Realism with a Human Face, Harvard University Press, Cambridge, MA.

Rouse, J. (1996). Engaging Science: How to Understand Its Practices Philosophically, Cornell University Press, Ithaca.

Rouse, J. (2002). How Scientific Practices Matter: Reclaiming Philosophical Naturalism, University of Chicago Press, Chicago.

Rouse, J. (2003). Kuhn's philosophy of scientific practice, in T. Nickles (ed.), Thomas Kuhn, Cambridge University Press, Cambridge, pp. 101-121.

Sharrock, W. and Read, R. (2002). Kuhn: Philosopher of Scientific Revolutions, Polity Press, Cambridge.

Vihalemm, R. (2011). Towards a practical realist philosophy of science, Baltic Journal of European Studies 1: 46-6o.

White, M. (1956). Toward Reunion in Philosophy, Harvard University Press, Cambridge.

White, M. (1986). Normative ethics, normative epistemology, and Quine's holism, in L. Hahn and P. Schlipp (eds), The Philosophy of W. V. Quine, Open Court, La Salle.

White, M. (2002). A Philosophy of Culture: The Scope of Holistic Pragmatism, Princeton University Press, Princeton. 